\title{
The Air Density Equation and the Transfer of the Mass Unit
}

\author{
Frank E. Jones \\ National Engineering Laboratory, National Bureau of Standards, Washington, D.C. 20234
}

June 29, 1978

\begin{abstract}
A new formulation of the equation for calculation of air density has been developed. The Cohen and Taylor value of the gas constant, currently accepted values of the atomic weights, and recent determinations of abundances of the various constituents of air have been used. The abundance of carbon dioxide has been treated as a variable and a factor enabling convenient adjustment of the apparent molecular weight of air for deviation of carbon dioxide abundance from a background value has been derived. A new table of the compressibility factor for the range of pressure and temperature of interest in standards laboratories has been calculated using recently determined values of virial coefficients. The enhancement factor, which has usually been ignored, has been explicitly included. A simple equation for the calculation of enhancement factor has been fitted to values in the range of pressure and temperature of interest. A simple equation for the calculation of saturation water vapor pressure has been fitted. Uncertainties, random and systematic, in the parameters and in the measurement of environmental variables and consequent uncertainties in calculated air density have been estimated.

Application of the equation to air buoyancy determination and the transfer of the mass unit at the various national standards laboratories has been made.
\end{abstract}

Key words: Air buoyancy; air density; mass unit transfer; real gas equation.

\section{Introduction}

The transfer of the mass value from one object, such as the International Prototype Kilogram, to another object is accomplished by comparison of the objects by means of a balance. The difference in buoyant force on the two objects is proportional to the difference in their displacement volumes and to the air density. The air density is conventionally calculated using an equation based on the equation of state of an air-water vapor mixture. A new formulation of the air density equation is developed below.

\section{Development of the Air Density Equation}

The total pressure, $P$, the total volume, $V$, and the absolute temperature, $T$, of a mixture of ideal gases are related by the ideal gas equation,

$$
P V=n R T,
$$

where $n$ is the number of moles of the mixture and $R$ is the universal gas constant. In terms of density, $\rho$, rather than volume, eq (1) becomes

$$
P=\rho \frac{R}{M} T,
$$

where $M$ is the apparent molecular weight of the mixture.
For a mixture of dry air (indicated by subscript $a$ ) and water vapor (subscript $w$ ), $\rho$ and $M$ are the density and apparent molecular weight respectively of the air-water vapor mixture. Since

$$
M=\frac{m}{n}=\frac{m_{a}+m_{w}}{n_{a}+n_{w}},
$$

where $m$ is the mass of the mixture and $n$ is the number of moles of the mixture,

$$
M=\frac{n_{a} M_{a}+n_{w} M_{w}}{n_{a}+n_{w}}=M_{a}\left(\frac{1+\frac{n_{w} M_{w}}{n_{a} M_{a}}}{1+\frac{n_{w}}{n_{a}}}\right) .
$$

By introducing the water vapor mixing ratio, $r$ :

$$
r=\frac{\text { mass of water vapor }}{\text { mass of dry air }}=\frac{n_{w} M_{w}}{n_{a} M_{a}},
$$

and by designating the ratio $\frac{M_{w}}{M_{a}}$ by $\epsilon$, eq (4) becomes

$$
M=\frac{M_{a}(1+r)}{\left(1+\frac{r}{\epsilon}\right)} .
$$


Substituting (6) in (2) and noting that the effective vapor pressure, $e^{\prime}$, of water in moist air is defined $[1]^{1}$ by:

$$
e^{\prime}=\frac{r}{(\epsilon+r)} P \text {, }
$$

then

$$
P=\rho \frac{R}{M_{a}} T\left[\frac{1}{1+(\epsilon-1) \frac{e^{\prime}}{P}}\right]
$$

Equation (8) is the ideal gas equation for a mixture of dry air and water vapor with a vapor pressure of $e^{\prime}$. If the air-water vapor mixture behaved as a mixture of ideal gases,

$$
\frac{P}{\rho \frac{R}{M_{a}} T\left[\frac{1}{1+(\epsilon-1) \frac{e^{\prime}}{P}}\right]}=Z=1,
$$

where $Z$ is the compressibility factor. Since the mixture is not ideal the magnitude of the non-ideality is reflected in the departure of $Z$ from 1 and (9) becomes

$$
P=\rho \frac{R}{M_{a}} T Z\left[\frac{1}{1+(\epsilon-1) \frac{e^{\prime}}{P}}\right]
$$

Equation (10) is the real gas equation for a mixture of dry air and water vapor. By rearrangement of eq (10), the expression for the air density is

$$
\rho=\frac{P M_{a}}{R T Z}\left[1+(\epsilon-1) \frac{e^{\prime}}{P}\right]
$$

\section{Specification of the Values of the Parameters in the Air Density Eq (1 11 )}

\subsection{Universal Gas Constant, $\mathbf{R}$}

The value of the molar gas constant, $R$, listed in a compilation by Cohen and Taylor [2], is 8.31441 \pm 0.00026 $\mathrm{JK}^{-1} \mathrm{~mol}^{-1}$. Recently, Quinn et al. [3] made a new determination of $R$ by measuring the speed of sound in argon by means of an acoustic interferometer. Their value was $8315.73 \pm 0.17 \mathrm{JK}^{-1} \mathrm{kmol}^{-1}$. Gammon [4] recently deduced a value of $R$ from measurements of the speed of sound in helium; his latest reported value is $8315.31 \pm 0.35 \mathrm{JK}^{-1}$ $\mathrm{kmol}^{-1}[5]$, which is in close agreement with the Quinn et al. value. Rowlinson and Tildesley [6] have recently interpreted

\footnotetext{
${ }^{1}$ Figures in brackets indicate references at the end of this paper.
}

the experimental measurements of Quinn et al. and arrived at a value of $8314.8 \pm 0.3 \mathrm{JK}^{-1} \mathrm{kmol}^{-1}$, which is in agreement with the Cohen and Taylor value within the uncertainties assigned to the values.

We choose at present to use the Cohen and Taylor value with the realization that in the future it might be replaced by a new value.

\subsection{Apparent Molecular Weight of Air, $M_{a}$}

The apparent molecular weight of dry air, $M_{a}$, is calculated using the relationship

$$
M_{a}=\sum_{i=1}^{k} M_{i} x_{i}
$$

where each $M_{i}$ is the molecular weight of an individual constituent and $x_{i}$ is the corresponding mole fraction. The molecular weights and typical mole fractions of the constituents of dry air are tabulated in table 1. Other constituents are present in abundances which are negligible for the present application.

The values of the atomic weights of the elements are taken from reference [7] and are based on the carbon- 12 scale. The molecular weights are taken to be the sums of the atomic weights of the appropriate elements.

The value for the abundance of oxygen is taken from reference [8]. The value for the abundance of carbon dioxide is taken from a recent unpublished compilation of data on atmospheric concentration of carbon dioxide at seven locations throughout the world. It must be emphasized that 0.00033 is the mole fraction of $\mathrm{CO}_{2}$ in the atmosphere and should be considered to be a "background" value. The mole fraction of $\mathrm{CO}_{2}$ in laboratories, which is of course the value of interest here, is in general greater than 0.00033 and is variable. For example, three samples of air taken from a glove box in the Mass Laboratory at NBS had a mean value of 0.00043 , and four samples of laboratory air taken at the National Center for Atmospheric Research in Boulder, Colorado had a mean value of 0.00080 . Clearly, then, the optimum utilization of the air density calculation would necessitate a measurement of $\mathrm{CO}_{2}$ abundance on an air sample taken at the time of the mass comparison.

One of the options one has in dealing with the variability of $\mathrm{CO}_{2}$ abundance is to select a reference level (for example, 0.00033 or 0.00043 ) and to provide an adjustment to $M_{a}$ to account for known departures from the reference level. Gluekauf [9], in discussing the variation of the abundance of oxygen in the atmosphere, stated that "all major variations of the $\mathrm{O}_{2}$ content must result from the combustion of fuel, from the respiratory exchange of organisms, or from the assimila- 
tion of $\mathrm{CO}_{2}$ in plants. The first process does not result in more than local changes of $\mathrm{O}_{2}$ content, while the latter two processes, though locally altering the $\mathrm{CO}_{2} / \mathrm{O}_{2}$ ratio, leave their sum unchanged." The assumed constancy of the sum of the $\mathrm{O}_{2}$ and $\mathrm{CO}_{2}$ abundance simplifies the adjustment of $M_{a}$ to account for departures from the $\mathrm{CO}_{2}$ reference level and simplifies the estimation of the uncertainty in air density due to an uncertainty in $\mathrm{CO}_{2}$ abundance. The constancy of the sum is expressed by the equation (for convenience, the subscript $i$ has been replaced by the chemical symbol):

$$
x_{\mathrm{CO}_{2}}+x_{\mathrm{O}_{2}}=\text { constant }=0.20979 .
$$

The contribution of $\mathrm{O}_{2}$ and $\mathrm{CO}_{2}$ to the apparent molecular weight of dry air is

$$
M_{\mathrm{O}_{2}} x_{\mathrm{O}_{2}}+M_{\mathrm{CO}_{2}} x_{\mathrm{CO}_{2}}=31.9988 x_{\mathrm{O}_{2}}+44.0098 x_{\mathrm{CO}_{2}} .
$$

From (13),

$$
x_{\mathrm{O}_{2}}=0.20979-x_{\mathrm{CO}_{2}},
$$

and

$$
M_{\mathrm{O}_{2}} x_{\mathrm{O}_{2}}+M_{\mathrm{CO}_{2}} x_{\mathrm{CO}_{2}}=12.011 x_{\mathrm{CO}_{2}}+6.7130 .
$$

Therefore,

$$
\begin{aligned}
\delta\left(M_{a}\right) & =\delta\left[M_{\mathrm{O}_{2}} x_{\mathrm{O}_{2}}+M_{\mathrm{CO}_{2}} x_{\mathrm{CO}_{2}}\right] \\
& =12.011 \delta\left(x_{\mathrm{CO}_{2}}\right),
\end{aligned}
$$

that is, the variation in $M_{a}$ due to a variation in $\mathrm{CO}_{2}$ abundance is equal to 12.011 (the atomic weight of carbon) multiplied by the variation in $\mathrm{CO}_{2}$ abundance. The variation in $M_{a}$ due to the difference between the reference levels 0.00033 and 0.00043 is thus $0.0012 \mathrm{~g} \mathrm{~mol}^{-1}$ which corresponds to a relative variation of 41 p.p.m. in $M_{a}$ and a corresponding relative variation of 41 p.p.m. in air density.

The adjusted $M_{a}$ accounting for the departure of the $\mathrm{CO}_{2}$ abundance from the reference level of 0.00033 becomes

$$
M_{a}=M_{a_{033}}+12.011\left[x_{\mathrm{CO}_{2}}-0.00033\right],
$$

where $M_{a_{033}}$ is the apparent molecular weight of dry air with a $\mathrm{CO}_{2}$ mole fraction of 0.00033 .

The value of the abundance of argon in dry air, 0.00916, is that calculated from the mass spectrometric determination of the ratio of argon to argon and nitrogen by Hughes [10].

The value for the abundance of nitrogen was arrived at by the usual practice of inferring nitrogen abundance to be the difference between unity and the sum of the mole fractions of the other constituents.

The abundances of the constituents neon through nitrous oxide in table 1 were taken to be equal to the parts per volume concentration in U.S. Standard Atmosphere, 1976 [11].

From the data of table 1, the apparent molecular weight of dry air with a $\mathrm{CO}_{2}$ mole fraction of 0.00033 is calculated by (12) to be 28.963 .

TABle 1. Composition of dry air

\begin{tabular}{l|c|c}
\hline \hline \multicolumn{1}{c|}{ Constituent } & $\begin{array}{c}\text { Abundance } \\
\text { (mole fraction) }\end{array}$ & $\begin{array}{c}\text { Molecular } \\
\text { Weight }\end{array}$ \\
\hline Nitrogen $\left(\mathrm{N}_{2}\right)$ & 0.78102 & 28.0134 \\
Oxygen $\left(\mathrm{O}_{2}\right)$ & .20946 & 31.9988 \\
Carbon Dioxide $\left(\mathrm{CO}_{2}\right)$ & .00033 & 44.0098 \\
Argon $(\mathrm{A})$ & .00916 & 39.948 \\
Neon $(\mathrm{Ne})$ & .00001818 & 20.179 \\
Helium $(\mathrm{He})$ & .00000524 & 4.00260 \\
Krypton $(\mathrm{Kr})$ & .00000114 & 83.80 \\
Xenon $(\mathrm{Xe})$ & .000000087 & 131.30 \\
Hydrogen $\left(\mathrm{H}_{2}\right)$ & .0000005 & 2.0158 \\
Methane $\left(\mathrm{CH}_{4}\right)$ & .0000015 & 16.0426 \\
Nitrous $\mathrm{Oxide}\left(\mathrm{N}_{2} \mathrm{O}\right)$ & .0000003 & 44.0128 \\
\hline
\end{tabular}

\subsection{Compressibility Factor, $\mathbf{Z}$}

The compressibility factor is computed using the virial equation of state of an air-water vapor mixture expressed as a power series in reciprocal molar volume,

$$
Z=\frac{P v}{R T}=1+\frac{B_{\text {mix }}}{v}+\frac{C_{\text {mix }}}{v^{2}}+\cdots \cdots,
$$

and expressed as a power series in pressure,

$$
Z=\frac{P v}{R T}=1+B_{\text {mix }}^{\prime} P+C_{\text {mix }}^{\prime} P^{2}+\cdots \cdots,
$$

where $v$ is the molar volume, $B_{\text {mix }}$ and $B_{\text {mix }}^{\prime}$ are second virial coefficients and $C_{\text {mix }}$ and $C_{\text {mix }}^{\prime}$ are third virial coefficients for the mixture. The virial coefficients of the pressure series are related to the virial coefficients of the volume power series by

$$
B_{\text {mix }}^{\prime}=\frac{B_{\text {mix }}}{R T}
$$

and

$$
C_{\text {mix }}^{\prime}=\frac{C_{\text {mix }}-B^{2}{ }_{\text {mix }}}{(R T)^{2}} .
$$

Each mixture virial coefficient is a function of the mole fractions of the individual constituents and the virial coefficients for the constituents. The latter are functions of temperature only. 
The second interaction (cross) virial coefficient of moist air, $B_{a w}$, is one of the contributors to $B^{\prime}{ }_{\text {mix }}$ and expresses the effects of interaction between an air molecule and a water molecule. The values of $B_{a w}$ used in the calculation of $Z$ are experimental values which strictly apply to $\mathrm{CO}_{2}$-free air.

Using (28) and (29), below, and the virial coefficients [12, 16] provided by Hyland, a table of compressibility factor, $Z$, for $\mathrm{CO}_{2}$-free air, table 2 , has been generated.

In the absence of values for virial coefficients for air- $\mathrm{CO}_{2}$ mixtures in the temperature range of interest, the effect of the variability of $\mathrm{CO}_{2}$ abundance on $Z$ has been estimated to be of the order of $1 \mathrm{ppm}$ and, therefore, negligible. Also, the effect of the variability of $\mathrm{CO}_{2}$ abundance on $Z$ due to the interaction of $\mathrm{CO}_{2}$ with water vapor has been estimated to be of the order of $0.1 \mathrm{ppm}$ and, therefore, negligible. Consequently, table 2 is applicable to moist air containing reasonable amounts of $\mathrm{CO}_{2}$.

For temperatures and/or pressures outside the range of table 2, the table of compressibility factor of moist air (also $\mathrm{CO}_{2}$-free) in the Smithsonian Meteorological Tables [15] can be used, with some loss of precision since the listing there is to the fourth decimal place.

\subsection{Ratio of the Molecular Weight of Water to the Molecular Weight of Dry Air}

The molecular weight of water is 18.0152 [7]. The ratio, $\epsilon$, of the molecular weight of water to that of dry air is, therefore, 0.62201 for dry air with a $\mathrm{CO}_{2}$ mole fraction of 0.00033 .

\section{Uncertainty in Calculation of Air Density}

In estimating uncertainties we shall report them as 1 standard deviation and we shall follow the suggested practice of Eisenhart [13, 14] in stating separately the random and systematic components.

\subsection{Uncertainty in $\mathbf{R}$}

The uncertainty in the value of the molar gas constant is that reported by Cohen and Taylor [2], $\pm 0.00026 \mathrm{JK}^{-1}$ $\mathrm{mol}^{-1}$. The corresponding random relative uncertainty in $\rho$ is $3.1 \times 10^{-5}$.

\subsection{Uncertainties in $M_{a}$}

The uncertainties in $M_{a}$ will be taken from the estimated uncertainties in particular measurements of the abundances of the constituents of air. The uncertainty in the $\mathrm{O}_{2}$ abundance (mole fraction) of air [8] is separable into a random component and a systematic component. The random uncertainty is estimated to be \pm 0.00001 , the systematic component is \pm 0.00006 .
TABLE 2. Compressibility factor, $z$, for $\mathrm{CO}_{2}$-free air

\begin{tabular}{|c|c|c|c|c|c|c|c|}
\hline $\begin{array}{c}\text { Temperature } \\
\text { (Celsius) }\end{array}$ & \multicolumn{2}{|c|}{ Pressure } & $0^{\operatorname{Re} 1}$ & $\begin{array}{l}\text { ative } \mathrm{Hu} \\
25\end{array}$ & $\begin{array}{c}\text { Iumidity } \\
50\end{array}$ & $\begin{array}{l}\text { in Percent } \\
75\end{array}$ & 100 \\
\hline 19.0 & $\begin{array}{r}70000 \\
75000 \\
80000 \\
85000 \\
90000 \\
95000 \\
100000 \\
101325 \\
105000 \\
110000\end{array}$ & $\begin{array}{l}525.0 \\
562.5 \\
600.0 \\
637.6 \\
675.1 \\
712.6 \\
750.1 \\
760.0 \\
787.6 \\
825.1\end{array}$ & $\begin{array}{r}.99973 \\
.99972 \\
.99970 \\
.99968 \\
.99966 \\
.99964 \\
.99962 \\
.99962 \\
.99960 \\
.99958\end{array}$ & $\begin{array}{l}.99972 \\
.99970 \\
.99968 \\
.99967 \\
.99965 \\
.99963 \\
.99961 \\
.99960 \\
.99959 \\
.99957\end{array}$ & $\begin{array}{l}.99971 \\
.99969 \\
.99967 \\
.99965 \\
.99963 \\
.99961 \\
.99959 \\
.99959 \\
.99958 \\
.99956\end{array}$ & $\begin{array}{l}.99968 \\
.99967 \\
.99965 \\
.99963 \\
.99961 \\
.99960 \\
.99958 \\
.99957 \\
.99956 \\
.99954\end{array}$ & $\begin{array}{l}.99966 \\
.99964 \\
.99963 \\
.99961 \\
.99959 \\
.99957 \\
.99956 \\
.99955 \\
.99954 \\
.99952\end{array}$ \\
\hline 20. & $\begin{array}{r}70000 \\
75000 \\
80000 \\
85000 \\
90000 \\
95000 \\
100000 \\
101325 \\
105000 \\
110000\end{array}$ & $\begin{array}{l}525.0 \\
562.5 \\
600.0 \\
637.6 \\
675.1 \\
712.6 \\
750.1 \\
760.0 \\
787.6 \\
825.1\end{array}$ & $\begin{array}{l}.99974 \\
.99972 \\
.99970 \\
.99969 \\
.99967 \\
.99965 \\
.99963 \\
.99963 \\
.99961 \\
.99959\end{array}$ & $\begin{array}{l}.99973 \\
.99971 \\
.99969 \\
.99967 \\
.99666 \\
.99964 \\
.99962 \\
.99961 \\
.99960 \\
.99958\end{array}$ & $\begin{array}{l}.99971 \\
.99969 \\
.99967 \\
.99966 \\
.99964 \\
.99962 \\
.99960 \\
.99960 \\
.99958 \\
.99957\end{array}$ & $\begin{array}{l}.99969 \\
.99967 \\
.99965 \\
.99964 \\
.99962 \\
.99960 \\
.99958 \\
.99958 \\
.99957 \\
.99955\end{array}$ & $\begin{array}{l}.99966 \\
.99964 \\
.99963 \\
.99961 \\
.99966 \\
.99958 \\
.99956 \\
.99956 \\
.99954 \\
.99953\end{array}$ \\
\hline 21.0 & $\begin{array}{r}70000 \\
75000 \\
80000 \\
85000 \\
90000 \\
95000 \\
100000 \\
101325 \\
105000 \\
110000\end{array}$ & $\begin{array}{l}525.0 \\
562.5 \\
600.0 \\
637.6 \\
675.1 \\
712.6 \\
750.1 \\
760.0 \\
787.6 \\
825.1\end{array}$ & $\begin{array}{l}.99975 \\
.99973 \\
.99971 \\
.99969 \\
.99968 \\
.99966 \\
.99964 \\
.99964 \\
.99962 \\
.99960\end{array}$ & $\begin{array}{l}.99973 \\
.99972 \\
.99970 \\
.99968 \\
.99966 \\
.99965 \\
.99963 \\
.99962 \\
.99961 \\
.99959\end{array}$ & $\begin{array}{l}.99971 \\
.99970 \\
.99968 \\
.99966 \\
.99965 \\
.99963 \\
.99961 \\
.99961 \\
.99959 \\
.99958\end{array}$ & $\begin{array}{l}.99969 \\
.99967 \\
.99966 \\
.99964 \\
.99962 \\
.99961 \\
.99959 \\
.99959 \\
.99957 \\
.99956\end{array}$ & $\begin{array}{l}.99966 \\
.99964 \\
.99963 \\
.99961 \\
.99960 \\
.99958 \\
.99956 \\
.99956 \\
.99955 \\
.99953\end{array}$ \\
\hline 22.0 & $\begin{array}{r}70000 \\
75000 \\
80000 \\
85000 \\
90000 \\
95000 \\
100000 \\
101325 \\
105000 \\
110000\end{array}$ & $\begin{array}{l}525.0 \\
562.5 \\
600.0 \\
637.6 \\
675.1 \\
712.6 \\
750.1 \\
760.0 \\
787.6 \\
825.1\end{array}$ & $\begin{array}{l}.99975 \\
.99974 \\
.99972 \\
.99970 \\
.99968 \\
.99967 \\
.99965 \\
.99965 \\
.99963 \\
.99962\end{array}$ & $\begin{array}{l}.99974 \\
.99972 \\
.99971 \\
.99969 \\
.99967 \\
.99965 \\
.99964 \\
.99963 \\
.99962 \\
.99960\end{array}$ & $\begin{array}{l}.99972 \\
.99970 \\
.99969 \\
.99967 \\
.99965 \\
.99963 \\
.99962 \\
.99961 \\
.99960 \\
.99958\end{array}$ & $\begin{array}{l}.99969 \\
.99968 \\
.99966 \\
.99964 \\
.99963 \\
.99961 \\
.99960 \\
.99959 \\
.99958 \\
.99956\end{array}$ & $\begin{array}{l}.99966 \\
.99964 \\
.99963 \\
.99961 \\
.99960 \\
.99958 \\
.99957 \\
.99956 \\
.99955 \\
.99954\end{array}$ \\
\hline 23. & $\begin{array}{r}70000 \\
75000 \\
80000 \\
85000 \\
90000 \\
95000 \\
100000 \\
101325 \\
105000 \\
110000\end{array}$ & $\begin{array}{l}525.0 \\
562.5 \\
600.0 \\
637.6 \\
675.1 \\
712.6 \\
750.1 \\
760.0 \\
787.6 \\
825.1\end{array}$ & $\begin{array}{r}.99976 \\
.99974 \\
.99973 \\
.99971 \\
.99969 \\
.99968 \\
.99966 \\
.99965 \\
.99964 \\
.99963\end{array}$ & $\begin{array}{l}.99975 \\
.99973 \\
.99971 \\
.99969 \\
.99968 \\
.99966 \\
.99964 \\
.99964 \\
.99963 \\
.99961\end{array}$ & $\begin{array}{l}.99972 \\
.99971 \\
.99969 \\
.99967 \\
.99966 \\
.99964 \\
.99962 \\
.99962 \\
.99961 \\
.99959\end{array}$ & $\begin{array}{l}.99969 \\
.99968 \\
.99966 \\
.99965 \\
.99963 \\
.99962 \\
.99960 \\
.99960 \\
.99958 \\
.99957\end{array}$ & $\begin{array}{r}.99966 \\
.99964 \\
.99963 \\
.99962 \\
.99960 \\
.99959 \\
.99957 \\
.99957 \\
.99956 \\
.99954\end{array}$ \\
\hline 24.0 & $\begin{array}{r}70000 \\
75000 \\
80000 \\
85000 \\
90000 \\
95000 \\
100000 \\
101325 \\
105000 \\
110000\end{array}$ & $\begin{array}{l}525.0 \\
562.5 \\
600.0 \\
637.6 \\
675.1 \\
712.6 \\
750.1 \\
760.0 \\
787.6 \\
825.1\end{array}$ & $\begin{array}{l}.99977 \\
.99975 \\
.99973 \\
.99972 \\
.99970 \\
.99968 \\
.99967 \\
.99966 \\
.99965 \\
.99964\end{array}$ & $\begin{array}{l}.99975 \\
.99973 \\
.99972 \\
.99970 \\
.99969 \\
.99967 \\
.99965 \\
.99965 \\
.99964 \\
.99962\end{array}$ & $\begin{array}{l}.99973 \\
.99971 \\
.99970 \\
.99968 \\
.99966 \\
.99965 \\
.99963 \\
.99963 \\
.99962 \\
.99960\end{array}$ & $\begin{array}{l}.99969 \\
.99968 \\
.99967 \\
.99965 \\
.99964 \\
.99962 \\
.99961 \\
.99960 \\
.99959 \\
.99957\end{array}$ & $\begin{array}{r}.99965 \\
.99964 \\
.99963 \\
.99962 \\
.99960 \\
.99959 \\
.99957 \\
.99957 \\
.99956 \\
.99954\end{array}$ \\
\hline 25.0 & $\begin{array}{r}70000 \\
75000 \\
80000 \\
85000 \\
90000 \\
95000 \\
100000 \\
101325 \\
105000 \\
110000\end{array}$ & $\begin{array}{l}525.0 \\
562.5 \\
600.0 \\
637.6 \\
675.1 \\
712.6 \\
750.1 \\
760.0 \\
787.6 \\
825.1\end{array}$ & $\begin{array}{l}.99977 \\
.99976 \\
.99974 \\
.99973 \\
.99971 \\
.99969 \\
.99968 \\
.99967 \\
.99966 \\
.99965\end{array}$ & $\begin{array}{l}.99976 \\
.99974 \\
.99972 \\
.99971 \\
.99969 \\
.99968 \\
.99966 \\
.99966 \\
.99964 \\
.99963\end{array}$ & $\begin{array}{l}.99973 \\
.99971 \\
.99970 \\
.99968 \\
.99967 \\
.99965 \\
.99964 \\
.99963 \\
.99962 \\
.99961\end{array}$ & $\begin{array}{l}.99970 \\
.99968 \\
.99967 \\
.99965 \\
.99964 \\
.99962 \\
.99961 \\
.99961 \\
.99960 \\
.99958\end{array}$ & $\begin{array}{r}.99965 \\
.99964 \\
.99963 \\
.99962 \\
.99960 \\
.99959 \\
.99958 \\
.99957 \\
.99956 \\
.99955\end{array}$ \\
\hline 2 & $\begin{array}{r}70000 \\
75000 \\
80000 \\
85000 \\
90000 \\
95000 \\
100000 \\
101325 \\
105000 \\
110000\end{array}$ & $\begin{array}{l}525.0 \\
562.5 \\
600.0 \\
637.6 \\
675.1 \\
712.6 \\
750.1 \\
760.0 \\
787.6 \\
825.1\end{array}$ & $\begin{array}{l}.99978 \\
.99976 \\
.99975 \\
.99973 \\
.99972 \\
.99970 \\
.99969 \\
.99968 \\
.99967 \\
.99966\end{array}$ & $\begin{array}{l}.99976 \\
.99975 \\
.99973 \\
.99971 \\
.99970 \\
.99968 \\
.99967 \\
.99966 \\
.99965 \\
.99964\end{array}$ & $\begin{array}{l}.99973 \\
.99972 \\
.99970 \\
.99969 \\
.99967 \\
.99966 \\
.99964 \\
.99964 \\
.99963 \\
.99961\end{array}$ & $\begin{array}{l}.99970 \\
.99968 \\
.99967 \\
.99966 \\
.99964 \\
.99963 \\
.99961 \\
.99961 \\
.99960 \\
.99959\end{array}$ & $\begin{array}{r}.99965 \\
.99964 \\
.99963 \\
.99961 \\
.99960 \\
.99959 \\
.99958 \\
.99957 \\
.99956 \\
.99955\end{array}$ \\
\hline
\end{tabular}


The random component of the uncertainty in the argon abundance is inferred from the precision of Hughes' measurements [10] to be \pm 0.00003 . No assignment of systematic uncertainty was made by Hughes.

The uncertainty in the $\mathrm{CO}_{2}$ abundance has been mentioned earlier with respect to the variability of the $\mathrm{CO}_{2}$ abundance in the laboratory. For a sample of air taken at the time a mass comparison is made, the estimated uncertainty in the subsequent mass spectrometric determination of $\mathrm{CO}_{2}$ abundance is \pm 0.00003 at the 0.00033 level. Since the measurements made by the mass spectrometric method are considered to be very precise, the estimated uncertainty is considered to be systematic.

Since the $\mathrm{N}_{2}$ abundance is the difference between unity and the sum of the mole fractions of the other constituents, the random component of the uncertainty in the $\mathrm{N}_{2}$ abundance is found by combining by quadrature the random components of the uncertainties of the other three major components to be $\pm 1 \times 10^{-5}$. For the systematic component, however, the practice of finding the $\mathrm{N}_{2}$ abundance by difference provides for very significant reduction of uncertainty. This is shown in the following treatment.

Equation (12) can be written:

$$
\begin{aligned}
M_{a}=M_{\mathrm{O}_{2}} x_{\mathrm{O}_{2}}+M_{\mathrm{CO}_{2}} x_{\mathrm{CO}_{2}} & \\
& +M_{A} x_{A}+M_{\mathrm{N}_{2}} x_{\mathrm{N}_{2}}+\sum_{1=5}^{k} M_{i} x_{i} .
\end{aligned}
$$

The mole fraction of $\mathrm{N}_{2}$ is, by difference,

$$
x_{\mathrm{N}_{2}}=1-x_{\mathrm{O}_{2}}-x_{\mathrm{CO}_{2}}-x_{A}-\sum_{1=5}^{k} x_{i} .
$$

If we ignore the last term in (28), differentiate and go to finite differences,

$$
\begin{aligned}
\Delta\left(M_{a}\right)_{x_{i}}= & M_{\mathrm{O}_{2}} \Delta x_{\mathrm{O}_{2}}+M_{\mathrm{CO}_{2}} \Delta x_{\mathrm{CO}_{2}} \\
& +M_{A} \Delta x_{A}+M_{\mathrm{N}_{2}} \\
& \left(-\Delta x_{\mathrm{O}_{2}}-\Delta x_{\mathrm{CO}_{2}}-\Delta x_{A}\right) \\
= & \left(M_{\mathrm{O}_{2}}-M_{\mathrm{N}_{2}}\right) \Delta x_{\mathrm{O}_{2}} \\
& +\left(M_{\mathrm{CO}_{2}}-M_{\mathrm{N}_{2}}\right) \Delta x_{\mathrm{CO}_{2}} \\
& +\left(M_{A}-M_{\mathrm{N}_{2}}\right) \Delta x_{A} .
\end{aligned}
$$

With the substitution of the appropriate systematic uncertainties and the molecular weights into (25), the systematic components of the relative uncertainty in $M_{a}$ due to uncertainties in abundance of the constituents if found to be \pm 3 $\times 10^{-5}$. The random component of the relative uncertainty is found to be $\pm 4 \times 10^{-5}$ by combining by quadrature the product of the molecular weight and the random component of uncertainty in abundance for each of the four major constituents and dividing by $M_{a}$. The uncertainty in $M_{a}$ due to the uncertainty in the value of the atomic or molecular weights of the $i$-th constituent is

$$
\Delta\left(M_{a}\right)_{M_{i}}=x_{i} \Delta M_{i}
$$

The uncertainties in the values of the atomic or molecular weights are inferred from reference [7]. ${ }^{2}$ For the four major constituents they are: for $\mathrm{O}_{2}, \pm 0.0002$; for $\mathrm{CO}_{2}, \pm 0.0005$; for $A, \pm 0.001$; and for $\mathrm{N}_{2}, \pm 0.0001$. These uncertainties are considered to be systematic. The sum of the four terms represented by (26) is \pm 0.0001 , corresponding to a relative uncertainty in $M_{a}$ of $\pm 4 \times 10^{-6}$.

The random component of the overall relative uncertainty in $M_{a}$ is, by quadrature, $\pm 4 \times 10^{-5}$. The systematic component of the overall relative uncertainty in $M_{a}$ is $\pm 3 \times$ $10^{-5}$, the sum of the component due to the systematic uncertainty in abundance and that due to the uncertainty in atomic or molecular weight. The corresponding random and systematic components of the relative uncertainty in $\rho$ are $\pm 4 \times 10^{-5}$ and $\pm 3 \times 10^{-5}$, respectively.

\subsection{Uncertainty in $Z$}

The uncertainty in $Z$, the compressibility factor, is estimated from the various uncertainties in $Z$ due to the uncertainties in the virial coefficients $[12,16]$. The estimated relative uncertainty in $Z$ at $293.15 \mathrm{~K}, 101325 \mathrm{~Pa}$ (1 atmosphere) and 50 percent relative humidity is $\pm 1.7 \times 10^{-5}$. The corresponding relative uncertainty, taken to be systematic, in $\rho$ is $\pm 1.7 \times 10^{-5}$.

\subsection{Uncertainty in $\epsilon$}

The uncertainty in $M_{w}$, the molecular weight of water, is \pm 0.0005 [7] and is treated here as systematic. The random component of the uncertainty in $\epsilon$, the ratio of $M_{w}$ to $M_{a}$, is calculated to be $\pm 1 \times 10^{-5}$ and the systematic component is estimated to be $\pm 8 \times 10^{-6}$. The corresponding uncertainties in the factor in (11) involving $\epsilon$,

$$
\left[1+(\epsilon-1) \frac{e^{\prime}}{P}\right]
$$

at $293.15 \mathrm{~K}, 101325 \mathrm{~Pa}$ and 50 percent relative humidity are $\pm 1 \times 10^{-7}$ and $\pm 9 \times 10^{-8}$, respectively. The corresponding relative uncertainties in the term and consequently in $\rho$ are $\pm 1 \times 10^{-7}$ and $\pm 9 \times 10^{-8}$, respectively.

\footnotetext{
${ }^{2}$ The uncertainty assigned in the reference is divided by 3 to estimate the uncertainty at 1 standard deviation.
} 


\subsection{Combined Relative Uncertainties in $\rho$ Due to the Uncertainties in $M_{a}, R, Z$ and $\epsilon$}

The random and systematic components of the relative uncertainty in $\rho$ at $293.15 \mathrm{~K}, 101325 \mathrm{~Pa}$ and 50 percent relative humidity, due to the uncertainties in $M_{a}, R, Z$ and $\epsilon$ are tabulated in table 3 .

TABLE 3. Components of the relative uncertainty in $\rho$ due to uncertainties in $M_{\mathrm{a}}, \mathrm{R}, \mathrm{Z}$ and $\epsilon$

\begin{tabular}{c|l|l}
\hline \hline Parameter & Random & \multicolumn{1}{|c}{ Systematic } \\
\hline$M \mathrm{a}$ & $\pm 4 \times 10^{-5}$ & $\pm 3 \times 10^{-5}$ \\
$R$ & $\pm 3.1 \times 10^{-5}$ & $-1.7 \times 10^{-5}$ \\
$Z$ & ------ & $\pm 1.7 \times 10^{-8}$ \\
$\epsilon$ & $\pm 1 \times 10^{-7}$ & $\pm 9 \times 10^{-5}$ \\
Combined & $\pm 5 \times 10^{-5}$ & $\pm 5 \times 10^{-5}$ \\
\hline
\end{tabular}

The random components were combined by quadrature, the systematic components were combined by addition. These components of uncertainty can be considered to represent the uncertainty "intrinsic" to the air density equation, that is, that which is contributed by the limitations on the present knowledge of $M_{a}, M_{w}, R$ and $Z$. With these uncertainties must, of course, be combined the uncertainties in the environmental variables: $P, T$ and relative humidity, and in the knowledge of the carbon dioxide abundance.

\section{Measurement of $P, T$ and Relative Humidity}

In order to estimate the uncertainties in $\rho$ due to uncertainties in the measurements of the environmental variables, $P, T$ and relative humidity, we shall estimate the uncertainties in these measurements when made using the best applicable instrumentation and procedures. Therefore, the estimated uncertainties in $\rho$ will be those contributed by the best possible measurements.

\subsection{Pressure Measurement}

The state-of-the-art in pressure measurement [17] permits the measurement of the pressure in a laboratory with a random relative uncertainty of less than $\pm 2 \times 10^{-4}$. Calibration of pressure measuring instruments against a primary standard of pressure contributes a systematic relative uncertainty of about $\pm 3 \times 10^{-5}$. The corresponding $\Delta \rho / \rho$ 's contributed by uncertainties in the measurement of pressure in a laboratory in the vicinity of a balance case are $\pm 2 \times$ $10^{-4}$ and $\pm 3 \times 10^{-5}$.

\subsection{Temperature Measurement}

The measurement of temperature in a balance case, that is the temperature which determines the buoyant forces, is potentially the most critical measurement in terms of its effect on the uncertainty in the calculated air density. In the absence of experimental results, it is possible at this time to make only a rough estimate of the temperature uncertainty to be expected. If the balance case were instrumented with a network of thermopile junctions, for example, the measurements would be expected to have a standard deviation of about $\pm 0.05 \mathrm{~K}$ [18]. The systematic uncertainty is estimated to be of the order of $\pm 0.01 \mathrm{~K}$. At a temperature of $293.15 \mathrm{~K}$, these uncertainties correspond to relative uncertainties of $\pm 2 \times 10^{-4}$, and $\pm 3 \times 10^{-5}$, respectively. The corresponding $\Delta \rho / \rho$ 's are $\pm 2 \times 10^{-4}$ and $\pm 3 \times 10^{-5}$, respectively.

\subsection{Humidity Measurements}

The state-of-the-art in humidity measurement [19] permits the measurement of humidity in a balance case with a random uncertainty of \pm 0.5 percent relative humidity and a systematic uncertainty of \pm 0.3 percent relative humidity. These uncertainties correspond to relative uncertainties in the water vapor pressure factor $\left[1+(\epsilon-1) e^{\prime} \mid P\right]$, in (11) and, therefore, to $\Delta \rho / \rho$, of $\pm 4 \times 10^{-5}$ and $\pm 3 \times 10^{-5}$ at 293.15K, $101325 \mathrm{~Pa}$ and 50 percent relative humidity.

Since $e^{\prime}$ is the effective vapor pressure of water in moist air, a word of caution with regard to inferring $e^{\prime}$ from measurements of relative humidity is in order. Relative humidity, $U$, can be defined [20] by

$$
U=\frac{e^{\prime}}{e_{s}^{\prime}} \times 100 \text { percent, }
$$

where $e^{\prime}{ }_{s}$ is the effective saturation vapor pressure of water in moist air. $e^{\prime}{ }_{s}$ is greater than $e_{s}$, the saturation vapor pressure of pure phase (i.e., water vapor without the admixture of air or any other substance) over a plane surface of pure ordinary liquid water, since the introduction of a second gas (air in this case) over the surface of the water increases the saturation concentration of water vapor above the surface of the water. This "enhancement" of water vapor pressure is expressed by the enhancement factor, $f$, which is defined by

$$
f=\frac{e_{s}^{\prime}}{e_{s}} .
$$

The most recently published [16] experimentally derived value of $f$ at $293.15 \mathrm{~K}$ and $100000 \mathrm{~Pa}$ is 1.00400 . Therefore, the common practice of inferring $e^{\prime}$ from measured $U$ and tabulated values of $e_{s}$ introduces a significant error in $e^{\prime}$ if $f$ has been ignored. The corresponding relative error in $\rho$ at $293.15 \mathrm{~K}, 101325 \mathrm{~Pa}$ and 50 percent relative humidity is about $1.7 \times 10^{-5}$.

$f$ is a function of temperature and pressure. In the present work, Hyland's values of $f[16]$ have been fitted to a three- 
parameter equation in the pressure and temperature $\left(t,{ }^{\circ} \mathrm{C}\right)$ ranges of interest in national standards laboratories. The resulting equation is

$$
f=1.00070+3.113 \times 10^{-8} P+5.4 \times 10^{-7} t^{2} .
$$

The expression for $e^{\prime}$ is found by combining (28) and (29) to be

$$
e^{\prime}=\frac{U}{100} f e_{s} .
$$

The systematic relative uncertainties in $\rho$ due to the uncertainties assigned to $f[16]$ and $e_{s}[22]$ are approximately $\pm 1 \times 10^{-6}$ and $\pm 2 \times 10^{-7}$, respectively.

For the temperature range of interest in the present application, any of several tables of $e_{s}$, for example, references [21], [22], and [23], can be used. Besley and Bottomley [24] have recently published experimental values of $e_{s}$ in the temperature range 272.60 to $298.04 \mathrm{~K}$.

In the present work, the data of Besley and Bottomley in the temperature range 288.15 to $298.04 \mathrm{~K}$ and calculated values [22] for the remainder of the temperature range to $301.15 \mathrm{~K}$, have been fitted to a two-parameter equation. The resulting equation is

$$
e_{s}=1.7526 \times 10^{11} \exp (-5315.56 / T) .
$$

Values calculated using (32) are sufficiently close to experimental and calculated values, within \pm 0.1 percent, to be used in the present application.

\subsection{Random and Systematic Components of the Relative Uncertainty in $\rho$ Due to Anticipated Uncertainties in State-of-the-Art Measurements of $P, T$ and Relative Humidity}

The random and systematic components of the relative uncertainty in $\rho$ at $293.15 \mathrm{~K}, 101325 \mathrm{~Pa}$ and 50 percent relative humidity due to anticipated uncertainties in state-ofthe-art measurements of the environmental variables are tabulated in table 4 . The random components were combined by quadrature, the systematic components were combined by addition.

It is clear from inspection of tables 3 and 4 that the dominant uncertainty in the calculation of air density is that contributed by the measurement of pressure, temperature and relative humidity, even when the measurements are made using the best instrumentation and procedures. Considerable care must therefore be taken in making measurements of these environmental variables in order to attempt to approach the precision and accuracy represented in table 4 .

To illustrate the effect of errors in the measurement of the environmental variables, at $293.15 \mathrm{~K}, 101325 \mathrm{~Pa}$ and 50 percent relative humidity, an error of 0.1 percent in calculated air density results from an error of $0.29 \mathrm{~K}$ in temperature measurement or a $101 \mathrm{~Pa}$ error in pressure measurement or an 11.3 percent relative humidity error in the measurement of relative humidity.

TABLE 4. Components of the relative uncertainty in $\rho$ due to anticipated uncertainties in state-of-the-art measurements of $P, T$ and relative humidity

\begin{tabular}{c|c|c}
\hline Variable & Random & Systematic \\
\hline$P$ & $\pm 2 \times 10^{-4}$ & $\pm 3 \times 10^{-5}$ \\
$T$ & $\pm 2 \times 10^{-4}$ & $\pm 3 \times 10^{-5}$ \\
Relative Humidity & $\pm 4 \times 10^{-5}$ & $\pm 3 \times 10^{-5}$ \\
Combined & $\pm 3 \times 10^{-4}$ & $\pm 9 \times 10^{-5}$ \\
\hline
\end{tabular}

\subsection{Carbon Dioxide Abundance}

As stated in section 3.2, the $\mathrm{CO}_{2}$ abundance in laboratory air and consequently in the air in balance cases is in general variable. A variation of 0.0001 in $\mathrm{CO}_{2}$ mole fraction is equivalent to a relative variation of $4 \times 10^{-5}$ in calculated air density. Consequently, for optimum utilization of the air density calculation, the $\mathrm{CO}_{2}$ abundance should be known. Equation (18) enables adjustment of $M_{a}$ for departures from the reference level, 0.00033 , of $\mathrm{CO}_{2}$ abundance.

\section{Overall Uncertainty in $\rho$ Due to Uncertainties in the Parameters and Variables in the Air Density Equation}

The random and systematic components of the relative uncertainties in $\rho$ in tables 3 and 4 when combined provide estimates of the components of the overall relative uncertainty in $\rho$. The random component, by quadrature, is \pm 3 $\times 10^{-4}$; the systematic component, by addition, is $\pm 1 \times$ $10^{-4}$. The relative uncertainty due to the variation of $\mathrm{CO}_{2}$ abundance $\left(4 \times 10^{-5}\right.$ per 0.0001 in $\mathrm{CO}_{2}$ mole fraction) is necessarily not included in this estimate.

At $293.15 \mathrm{~K}, 101325 \mathrm{~Pa}$ (1 atmosphere), and 50 percent relative humidity, the estimated overall relative uncertainties in $p$ correspond to uncertainties in mass in the transfer between platinum-iridium and stainless steel kilogram artifacts (volume difference of $\sim 80 \mathrm{~cm}^{3}$ ) of approximately $30 \mu \mathrm{g}$ random and $10 \mu \mathrm{g}$ systematic.

\section{Air Density at Standard Conditions, $\rho_{0}$}

The air density, $\rho_{0}$, at standard conditions $\left(P_{O}, M_{a_{O}}, R\right.$, $T_{O}, Z_{O}$ ), for dry air is expressed by an equation of the form of (11) as

$$
\rho_{O}=\frac{P_{o} M_{a_{O}}}{R T_{O} Z_{O}} .
$$


By dividing (11) by (33) we arrive at

$\rho=\rho_{o}\left(\frac{P}{P_{O}}\right)\left(\frac{T_{o}}{T}\right)\left(\frac{Z_{O}}{Z}\right)\left(\frac{M_{a}}{M_{a_{o}}}\right)$

$$
\left[1+(\epsilon-1) \frac{e^{\prime}}{P}\right] .
$$

The gas constant, $R$, has been eliminated but $M_{a}$ has not unless the apparent molecular weight of the dry air in the standard state, $M_{a_{0}}$ is equal to $M_{a}$. For example, if the $\rho_{O}$ is determined by experiment, $M_{a_{0}}$ is not necessarily equal to $M_{a}$.

If an experimental value of $\rho_{O}$ of sufficient accuracy were available in the determination of which $R$ was not used, $R$ and its associated uncertainty would be eliminated. In the absence of such an experimental value, as is the present case, the use of an equation combining (11) with (18) is preferred to an equation of the form of (34).

If standard conditions are taken to be $T_{O}=273.15 \mathrm{~K}, P_{O}$ $=101325 \mathrm{~Pa}, M_{a_{0}}=28.963$, and relative humidity $=0$, for which $Z_{O}=0.99940, \rho_{O}$ is calculated by (33) to be $1.2930 \mathrm{~kg} \mathrm{~m}^{-3}$. The same result is obtained for $M_{a}=28.964$ (i.e., for a $\mathrm{CO}_{2}$ mole fraction of 0.00043 ).

\section{Air Density Equation}

By combining (11) and (31) and substituting $\frac{M_{w}}{M_{a}}$ for $\epsilon$, the air density equation developed in this work becomes

$$
\left.\rho=\frac{P M_{a}}{R T Z}\left[1-\left(1-\frac{M_{w}}{M_{a}}\right) \frac{U}{100} \frac{f e_{s}}{P}\right)\right] .
$$

By substituting the Cohen and Taylor value of $R, 8314.41$ ( $K^{-1} \mathrm{kmol}^{-1}$ ), the value 18.0152 for $M_{w}$ and the value 28.963 for $M_{a_{033}}$ in (18), (35) becomes

$$
\begin{aligned}
\rho=0.000120273 \frac{P M_{a}}{T Z} & \\
& {\left[1-\left(1-\frac{18.0152}{M_{a}}\right) \frac{U}{100} \frac{f e_{s}}{P}\right], }
\end{aligned}
$$

where

$$
M_{a}=28.963+12.011\left[x_{\mathrm{CO}_{2}}-0.00033\right] .
$$

For $T=293.15 \mathrm{~K}, P=101325 \mathrm{~Pa}, 50$ percent relative humidity and $M_{a}=28.964 \mathrm{~g} \mathrm{~mol}^{-1}$, the air density calculated using (36) is $1.1993 \mathrm{~kg} \mathrm{~m}^{-3}$.

\subsection{Use of Constants in the Air Density Equation}

In this section we shall investigate the effect on mass comparisons of the use of appropriate constant values of $f, Z$ and $M_{a}$ in (36).

The buoyant effect of the displacement of air by a mass artifact is proportional to the density of the air, $\rho$, and the displacement volume, $V_{m}$, of the artifact. We define here the buoyancy correction, $m_{b}$, to be added to the observed mass, by the following equation:

$$
m_{b}=\rho V_{m}=\rho \frac{m}{\rho_{m}},
$$

where $m$ and $\rho_{m}$ are the mass and density, respectively, of the artifact.

The variation, $\Delta m_{b}$, in $m_{b}$ due to a relative uncertainty, $\Delta \rho / \rho$, in air density can be written

$$
\Delta m_{b}=\frac{m}{\rho_{m}}\left(\frac{\Delta \rho}{\rho}\right) \rho .
$$

By substituting a nominal value of $\rho, 1.2 \mathrm{~kg} \mathrm{~m}^{-3}$, in (39) we arrive at

$$
\Delta m_{b}=1.2 \frac{m}{\rho_{m}}\left(\frac{\Delta \rho}{\rho}\right) .
$$

We shall return to this equation to estimate the uncertainty in mass comparisons due to the use of certain constants in (36) for the calculation of air density.

To estimate the effect of a variation in $f$ about a selected constant value, nominal values of $P, T, M_{a}, Z$, relative humidity and $e_{s}$ are substituted in (36) and the resulting equation is differentiated with respect to $f$. Nominal values appropriate to the Mass Laboratory of NBS are $P=100000$ $\mathrm{Pa}, T=298.15 \mathrm{~K}, M_{a}=28.964 \mathrm{~g} \mathrm{~mol}^{-1}, 30$ percent relative humidity and $e_{s}=3169 \mathrm{~Pa}$. The resulting equation is

$$
\rho=1.1688(1-0.003594 f)
$$

and

$$
\frac{\Delta \rho}{\rho}=-0.0036 \frac{\Delta f}{f}
$$

The values of $f$ range from 1.0030 to 1.0046 , therefore the maximum $\Delta f / f$ for a nominal value of $f$ of 1.0042 is equal to $1.2 \times 10^{-3}$. The corresponding $\Delta \rho / \rho$ is equal to $4.3 \times 10^{-6}$.

To estimate the effect of a variation of $Z$ about a selected constant value, from (36), 


$$
\frac{\Delta \rho}{\rho}=\frac{-\Delta Z}{Z} .
$$

To estimate the expected variation in $Z$, it is necessary to estimate the ranges of the environmental variables, $P, T$ and relative humidity. The maximum and minimum of the atmospheric pressure at NBS, taken from climatological records of the National Weather Service of the National Oceanic and Atmospheric Administration and adjusted to the elevation of the Mass Laboratory, are 103850 and $96160 \mathrm{~Pa}$. The expected ranges in temperature and relative humidity are taken to be 18 to $28{ }^{\circ} \mathrm{C}$ and 10 to 50 percent, respectively. For the nominal values given in this section, the expected variations in the environmental variables result in a variation of $Z$ between 0.99957 and 0.99971 . These extremes in $Z$ correspond to relative variations in $Z$ about the nominal value, 0.99966 of $-9 \times 10^{-5}$ and $5 \times 10^{-5}$, respectively. The corresponding $\frac{\Delta \rho}{\rho}$, s are $9 \times 10^{-5}$ and $-5 \times 10^{-5}$.

As was shown in section 3.2 , a variation of 0.0001 in $\mathrm{CO}_{2}$ mole fraction corresponds to a relative variation in $M_{a}$ of 4 $\times 10^{-5}$ and to a $\Delta \rho / \rho$ of $4 \times 10^{-5}$.

Combining by quadrature the maximum values of $\Delta \rho / \rho$ due to expected variations in $f$ and $Z$ and variation of 0.0001 in $\mathrm{CO}_{2}$ mole fraction, the result is $9.9 \times 10^{-5}$. This is the value to be used in (39). Since the values combined are maximum values, the combined value can be considered loosely to approximate 3 standard deviations.

For various materials of interest in the comparison of mass artifacts, $\Delta m_{b}$ in micrograms $(\mu \mathrm{g})$ has been calculated using (39) and $1 \mathrm{~kg}$ and $100 \mathrm{~g}$ artifacts and tabulated in table 5.

TABLE 5. Variation in the buoyancy correction, $\Delta m_{\mathrm{b}}$, resulting from the use of constant values of $f, Z$ and $M_{\mathrm{a}}$ in (36)

\begin{tabular}{l|c|c}
\hline \hline \multicolumn{1}{c|}{ Material } & $\Delta m_{b}(\mu \mathrm{g})$ & $\Delta m_{b}(\mu \mathrm{g})$ \\
\cline { 2 - 3 } & $1 \mathrm{~kg}$ & $100 \mathrm{~g}$ \\
\hline Platinum-iridium & 5.5 & 0.55 \\
Stainless steel & 15 & 1.5 \\
Silicon & 54 & 5.4 \\
Brass & 14 & 1.4 \\
Aluminum & 44 & 4.4 \\
Tantalum & 7.1 & 0.71 \\
Water & 119 & 12 \\
\hline
\end{tabular}

The variation in the apparent mass difference between mass artifacts due to the use of constant values of $f, Z$ and $M_{a}$ is equal to the difference in $\Delta m_{b}$ for the artifacts. For example, for a comparison of kilogram artifacts of platinumiridium and stainless steel the variation in the apparent difference in their masses is $15-5.5=9.5 \mu \mathrm{g}$.

On the basis of the values calculated using table 5 and the precision of the balance used for mass comparisons, a judgment can be made concerning the adequacy of the use of constant values of $f, Z$ and, $M_{a}$ in (36). The precision of the balance used for the comparisons of $1 \mathrm{~kg}$ mass artifacts at NBS is $25 \mu \mathrm{g}$ at the 1 standard deviation level. Thus it can be concluded, for example, that constant values can be used in the comparison of platinum-iridium and stainless steel artifacts, and stainless steel and brass kilogram artifacts, but not for comparison of platinum-iridium and silicon kilogram artifacts. The precision of the kilogram balance at the Bureau International des Poids et Mesures (BIPM) is $1.5 \mu \mathrm{g}$ at the 1 standard deviation level, therefore it could be concluded that the use of constants would not be appropriate in mass comparisons made using that balance.

For mass comparisons in the Mass Laboratory of NBS for which the values in table 5 indicate that the use of constant values of $f(1.0042), Z(0.99966)$ and $M_{a}(28.964)$ in (36) is adequate, the resulting equation is

$$
\rho=\frac{0.0034848}{T}\left(P-0.0037960 U e_{s}\right) .
$$

For pressure in millimeters of mercury and temperature, $t$, in ${ }^{\circ} \mathrm{C}$, (43) becomes

$$
\rho=\frac{0.46460}{(t+273.15)}\left(P-0.0037960 U e_{s}\right) .
$$

For saturation water vapor pressure, $e_{s}$, in millimeters of mercury (32) becomes

$$
e_{s}=1.3146 \times 10^{9} \exp (-5315.56 /(t+273.15)) .
$$

\section{Conclusions}

The following are recommendations concerning the transfer of the mass unit at the various national standards laboratories: 1) eq (36) should be adopted for use for all national standards laboratories to provide both uniformity and the best available calculation of air density; 2) the $\mathrm{CO}_{2}$ concentration should be treated as a variable and at least a "background" value should be determined for each of the laboratories; 3) instrumentation and practices representing the state-of-the-art in the measurement of the environmental variables should be applied.

The author gratefully acknowledges the invaluable contributions of R. W. Hyland in several areas, and especially with the calculation of the compressibility factor; the considerable computational work of C. L. Carroll, Jr.; and the typing of the manuscript by Kathy Durant. 


\section{References}

[1] List, R. J., Smithsonian Meterological Tables, 6th rev. ed. (The Smithsonian Institution, Washington, D. C., 1951), p. 347.

[2] Cohen, E. R., and Taylor, B. N., J. Phys. Chem. Ref. Data, 2, 663 (1973).

[3] Quinn, T. J., Colclough, A. R., and Chandler, T. R. D., Phil. Trans. Royal Society of London A283, 367 (1976).

[4] Gammon, B. E., J. Chem. Phys. 64, 2556 (1976).

[5] Gammon, B. E., Private communication.

[6] Rowlinson, J. S., and Tildesley, D. J., Proc. R. Soc. Lond. A358, 281 (1977).

[7] International Union of Pure and Applied Chemistry, Inorganic Chemistry Division, Commission on Atomic Weights, Pure and Appl. Chem. 47, 75 (1976).

[8] Machta, L., and Hughes, E., Science 168, 1582 (1970)

[9] Gluekauf, E., Compendium of Meteorology, Malone, T. F., Editor (The American Meteorological Society, Boston, Mass., 1951) p. 4.

[10] Hughes, E., Unpublished, but presented orally at the American Chemical Society Fourth Mid-Atlantic Meeting, Washington, D. C. (Feb. 1969).

[11] U. S. Standard Atmosphere, 1976, (U. S. Government Printing Office, Washington, D. C., 1976), pp. 3 and 33.
[12] Hyland, R. W., and Wexler, A., J. Res. Nat. Bur. Stand. (U. S.), 77A (Phys. and Chem.) No. 1, 133-147 (Jan.-Feb. 1973).

[13] Eisenhart, C., J. Res. Nat. Bur. Stand (U.S.), 67C (Eng. and Instr.), No. 2, 161-187 (April-June 1963).

[14] Eisenhart, C., Science 160, 1201 (1968).

[15] List, R. J., loc. cit., p. 333.

[16] Hyland, R. W., J. Res. Nat. Bur. Stand. (U.S.), 79A (Phys. and Chem.), No. 4, 551-560 (July-Aug. 1975).

[17] Heydemann, P. L. M., Private communication.

[18] Roeser, W. F., and Wensel, H. T., Temperature, Its Measurement and Control in Science and Industry, American Institute of Physics, National Bureau of Standards, National Research Council (Reinhold, New York, 1941), p. 311.

[19] Wexler, A., Meteorological Abstracts 11, 262 (1970).

[20] Harrison, L. P., Humidity and Moisture, Vol. III, Wexler, A., and Wildhack, W. A., Editors (Reinhold, New York 1964), p. 51.

[21] List, R. J., loc. cit., p. 352.

[22] Wexler, A., and Greenspan, L., J. Res. Nat. Bur. Stand. (U.S.), 75A, (Phys. and Chem.), No. 3, 213-230 (May-June 1971).

[23] Ambrose, D., and Lawrenson, I. J., Chem. Thermodynamics 4, 755 (1972).

[24] Besley, L., and Bottomley, G. A., J. Chem. Thermodynamics 5, 397 (1973). 